\title{
Human Saliva and Dried Saliva Spots as Source of DNA for PCR based HLA Typing using a Combination of Taq DNA Polymerase and AccuPrimeTaq Polymerase
}

\author{
Prerana Madhusudhana MURTHY ${ }^{1}$, Anupama Cheleri NEDUVAT ${ }^{1}$, \\ Cheemalamarri VEENADHAR ${ }^{2}$, Sudarson SUNDARRAJAN ${ }^{1}$ and \\ Sriram PADMANABHAN ${ }^{1, *}$
}

${ }^{1}$ Cancyte Technologies, Sri Shankara Research Center, Rangadore Memorial Hospital, Shankarapuram, Bangalore 560004, India

${ }^{2}$ Sir Ronald Ross Institute of Tropical and Communicable Diseases, Hyderabad, Andhra Pradesh, India

('Corresponding author's e-mail: sriram.padmanabhan@cancyte.com, padsriram@gmail.com)

Received: 17 September 2017, Revised: 25 February 2018, Accepted: 15 March 2018

\begin{abstract}
Genomic DNA extracted from human saliva samples showed high inter-subject variations in DNA yield, compelling the need to explore a methodology for the accurate quantitation of the extracted genomic DNA. Quantitative assessment of DNA extracted from saliva was achieved using human coagulation factor XIII as an internal control for subsequent downstream applications of amplification of human leucocyte antigen (HLA) genes by PCR. The PCR signals for the HLA target genes, namely, HLA-A, -B, -C , DPB1, DQB1, and DRB1 of exons 2 and 3, improved greatly with the use of a combination of Taq DNA polymerase and AccuPrimeTaq DNA polymerase. We also describe a new method of using dried saliva spots (DSS) as an alternate source of genomic DNA for HLA typing. PCRbased typing of DNA from human saliva offers a potential method for HLA typing and amplification, and typing of DNA, thus presented, could be applied in forensic science to saliva samples recovered from crime scenes.
\end{abstract}

Keywords: Saliva, HLA, PCR, NanoDrop, Whatman 903, Salting-out method

\section{Introduction}

The human major histocompatibility complex (MHC), located on the short arm of chromosome 6, is the most polymorphic genetic system in humans. The most intensely-studied HLA genes are the 9 socalled classical MHC genes: HLA-A, HLA-B, HLA-C, HLA-DPA1, HLA-DPB1, HLA-DQA1, HLADQB1, HLA-DRA, and HLA-DRB1. The class I region contains the classical $H L A-A, H L A-B$, and $H L A-$ $C$ genes, while the polymorphisms of class II molecules occur in the first amino terminal $\beta_{1}$ domain of $D R B 1, D Q B 1$, and $D P B 1$ gene products [1]. Genetic variation in the HLA genes is associated with susceptibility to autoimmune and infectious diseases and plays a major role in transplant immunology [2], hence, accurate allele typing of HLA helps in successful organ and bone marrow transplantations.

For HLA typing, the common method employed is to first obtain genomic DNA from nucleated cells of peripheral blood; although other alternative sources of DNA isolation, including saliva, buccal cells, hair follicles, urine, etc., have also been reported [3].

Human saliva contains proteins, hormones, antibodies, and other molecular compounds which are typically measured in routine blood tests [4], and acts as a promising diagnostic fluid with potential uses in disease detection and epidemiological studies $[5,6]$. Use of saliva for HLA typing has also been described, where typing of HLA class II genes from saliva was carried out by Kojima et al. [7], and 
Terasaki et al. [8] and Allen et al. [9] report the use of saliva traces from stamps and envelopes using HLA-DRB1 polymorphism as biological evidences in forensic cases.

After HLA amplicons from the donor and recipients is generated by PCR using sequence-specific oligonucleotide (SSO), sequence-specific primer (SSP), and sequence-based typing (SBT) technologies, the next step regularly followed is DNA sequencing by Sanger Sequencing or by Next-Generation Sequencing (NGS). In the latter method, the differences between the numbers of reads for each locus of a single sample is avoided, since imbalances during the equimolar pooling stages prior to library preparation results in some loci being over- or under-represented. Hence, for PCR based HLA typing, one needs to ensure the use of correct and optimal amounts of template for a successful NGS with the least ambiguity.

Internal controls are used as indicators of perfect nucleic acid extraction, quality of samples, and quality of PCR. Internal Control (IC) detects inhibitors of PCR and is required to monitor the integrity of the target nucleic acid in the specimen. A normal cellular gene sequence, which is expected to be present in all specimens, can be used as an IC. In our laboratory, we have observed that the human coagulation factor XIII (F13) gene [10] serves as an ideal IC gene for accurate determination of the genomic DNA quantity in a preparation (Neduvat et al. 2017, unpublished data). The current paper highlights that such an internal control holds the promise of accessing quality salivary genomic DNA (gDNA) too.

We also investigate a new method for storing saliva samples as dried saliva spots on filter papers, and share the data demonstrating that dried saliva spots (DSS) serve as an efficient source of gDNA for PCR based HLA typing.

\section{Materials and methods}

Oligonucleotides used in this study was procured from BioServe Technologies Pvt. Ltd, Hyderabad, India. Whatman 903 Protein saver card was from GE Healthcare, USA. Chelex-100 and other chemicals, such as ethylene diamine tetra acetic acid (EDTA), zinc acetate, sodium acetate, and isopropanol (IPA), were from Sigma Chemical Co, St. Louis, USA. AccuPrimeTaq DNA polymerase was procured from Invitrogen, USA, while Taq DNA polymerase was from ThermoFisher Scientific, USA.

\section{Preparation of Saliva Stabilization Buffer (SSB)}

To make the entire process of HLA typing cost-effective, we developed our own buffer that would help stabilize the saliva samples. The buffer included the use of $10 \mathrm{mM}$ Tris. Cl, pH 8.0, $100 \mathrm{mM}$ EDTA, and $500 \mathrm{mM}$ zinc acetate. The resultant $\mathrm{pH}$ of the SSB was 5.5.

\section{Sampling of Saliva}

Prior to obtaining the saliva sample, the donors were asked to rinse their mouths with clean water for $10 \mathrm{~s}$, with the water discarded. After waiting $5 \mathrm{~min}$, each donor salivated nearly $1 \mathrm{ml}$ of saliva into a clean polypropylene tube (collector) that had a simple screw-on funnel for delivery of the saliva directly into the collector tube containing SSB buffer. The saliva collection tube had graduation to indicate the volume of saliva required, after which the funnel was removed and discarded, and the cap screwed back safely. The saliva containing samples were stored at $4{ }^{\circ} \mathrm{C}$ until further use.

\section{DNA extraction}

The protocol by Suguna et al. [11] was followed for gDNA isolation from saliva samples with minor modifications. Briefly, 1ml of saliva in SSB was treated with $900 \mu \mathrm{l}$ of TKM1 buffer and $100 \mu 1$ of $1 \%$ Triton-X-100, vortexed and incubated at $37{ }^{\circ} \mathrm{C}$ for $5 \mathrm{~min}$. The contents were centrifuged at 8,000 rpm for $3 \mathrm{~min}$ and the above step was repeated, with washing of the pellet with $900 \mu 1$ of TKM1 buffer and $80 \mu 1$ of $1 \%$ Triton-X-100. The resultant pellet was then treated with $300 \mu \mathrm{l}$ of TKM2 and $40 \mu 110$ $\%$ SDS and the contents were vortexed and incubated at $37{ }^{\circ} \mathrm{C}$ for $5 \mathrm{~min}$, after which $100 \mu \mathrm{l}$ of $5 \mathrm{M} \mathrm{NaCl}$ was added and mixed thoroughly for precipitation of salivary proteins. The DNA from the supernatant obtained after centrifugation of the contents at $8,000 \mathrm{rpm}$ for $3 \mathrm{~min}$ was precipitated using $300 \mu \mathrm{l}$ of isopropanol and $30 \mu \mathrm{l}$ of $3 \mathrm{M}$ sodium acetate, $\mathrm{pH}$ 5.3. The DNA pellet was then washed with cold $70 \%$ 
http://wjst.wu.ac.th

ethanol and spun at 8,000 rpm for $5 \mathrm{~min}$. The pellet obtained was air dried, and the gDNA re-suspended in $50 \mu \mathrm{l}$ of TE buffer. The gDNA yield was measured using NanoDrop spectrophotometer, and the purity of the DNA preparations was estimated based on $\mathrm{A}_{260} / \mathrm{A}_{280}$ ratio, unless mentioned otherwise.

\section{HLA PCR}

Human leukocyte antigens (HLA), encoded by genes within the major histocompatibility complex (MHC), displays a high degree of polymorphism within the class I and class II genes that are usually used for HLA typing [12,13]. gDNA samples of $40 \mathrm{ng} / \mu \mathrm{l}$ were used as template to assess the relative efficiency of the preparations on HLA PCR of Class I genes, namely exons 2 and 3 of HLA-A, -B, and C. PCR was carried out in $25 \mu \mathrm{l}$ reaction volume, and the PCR mixture comprised $1 \mathrm{X}$ ammonium sulphate buffer, $\mathrm{pH}$ 8.3, $2.5 \mathrm{mM}$ magnesium chloride, $0.2 \mathrm{mM}$ dNTPs, $5 \%$ DMSO, 2 \% Tween-20, 0.32 $\%$ BSA, and $0.4 \mu \mathrm{M}$ of HLA gene specific primers. The HLA-A PCR was carried out for HLA-A-exon2 and 3 (reactions 1 and 2), HLA-B-exon2 and 3 (reactions 3 and 4), HLA-C-exon2 and 3 (reactions 5 and 6), HLA-DPB1, exons 2 and 3 (reactions 7 and 10), HLA-DQB1, exons 2 and 3 (reactions 8 and 11) and HLA-DRB1, exons 2 and 3 (reactions 9 and 12). The PCR cycling included an initial denaturation of 95 ${ }^{\circ} \mathrm{C}, 5 \mathrm{~min}$, followed by 40 cycles of denaturation step of $95{ }^{\circ} \mathrm{C}, 30 \mathrm{~s}$, suitable melting temperature $(\mathrm{Tm})$, $30 \mathrm{~s}$ and $72{ }^{\circ} \mathrm{C}, 45 \mathrm{~s}$ with a final extension step at $72^{\circ} \mathrm{C}$ for $10 \mathrm{~min}$. For reactions $2,4,5,7,8,10$, and 11 , Tm was $51.1{ }^{\circ} \mathrm{C}$, while for reactions 3 and 9 , it was 60 and $61.4{ }^{\circ} \mathrm{C}$, respectively. The Tm for reactions 1 , 6 , and 12 was $65^{\circ} \mathrm{C}$. The primers used for HLA PCR reactions were according to Lange et al. [13] and Itoh et al. [14] (Table 1). For PCR with 2 polymerases, $0.2 \mu \mathrm{l}$ of AccuPrimeTaq and 1U of Taq polymerase were used per reaction. All the PCR amplified products were examined on $2 \%$ agarose gel stained with ethidium bromide.

Table 1 Oligonucleotide sequences used in this study

\begin{tabular}{|c|c|c|c|}
\hline S.N. & Primers (5' to 3') & Target gene and direction & Amplicon size (bp) \\
\hline 1 & CCCCAGGCTCCCACTCCATG & $H L A-A$-exon 2 Forward & 375 \\
\hline 2 & GATCTCGGACCCGGAGACTGT & $H L A$ - $A$-exon2 Reverse & \\
\hline 3 & GGGCTGACCGCGGGGT & $H L A-A$-exon 3 Forward & 327 \\
\hline 4 & GTGGCCCCTGGTACCCGT & $H L A$ - $A$-exon 3 Reverse & \\
\hline 5 & GCCCCCAGGCTCCCACTC & $H L A-B$-exon 2 Forward & 378 \\
\hline 6 & CGATCTCGGACCTAGAGACTCG & $H L A$ - $B$-exon 2 Reverse & \\
\hline 7 & CGGGGCTGACCGCGGGGC & $H L A-B$-exon 3 Forward & 371 \\
\hline 8 & AGGCCATCCCCGCCGACCTAT & $H L A$ - $B$-exon3 Reverse & \\
\hline 9 & AGTCGACGAADCGGCCTCTGSGGA & $H L A-C$-exon 2 Forward & 422 \\
\hline 10 & ACTCGAGGGGCYGGGGTCACTCAC & $H L A-C$-exon2 Reverse & \\
\hline 11 & TCGACCGGAGAGAGCCCCAGT & $H L A-C$-exon 3 Forward & 428 \\
\hline 12 & CACTGCCCCTGGTACCCGC & $H L A-C$-exon3 Reverse & \\
\hline 13 & GGAAAGAAGGACAATCTCAAATTC & $H L A-D P B 1$-exon2 Forward & 368 \\
\hline 14 & GAGGGTCATCAGAGACTCA & $H L A-D P B 1$-exon2 Reverse & \\
\hline 15 & TTTTCCTGTCTGTTACTG & $H L A-D Q B 1$-exon 2 Forward & 350 \\
\hline 16 & CCATAGTAACAGAAACTCAA & $H L A-D Q B 1$-exon2 Reverse & \\
\hline 17 & TCCTGACTCATTCCCTCTACCT & $H L A$-DRB1-exon2 Forward & 351 \\
\hline 18 & GAAGTCAGAAAGCTGCTC & $H L A-D R B 1$ - exon2 Reverse & \\
\hline 19 & GAGGATTAGATGAGAGTGGCGCCT & $H L A-D P B 1$-exon3 Forward & 426 \\
\hline 20 & CGGCACTAAGGTCCCTTAGGCCA & $H L A-D P B 1$-exon 3 Reverse & \\
\hline 21 & CTGACTGACCGGCCGGTGATT & $H L A-D Q B 1$-exon3 Forward & 324 \\
\hline 22 & TCTCGGCCAAGGGTGGG & $H L A-D Q B 1$-exon3 Reverse & \\
\hline 23 & ATCCTTCGTGTCCCCACAGCA & $H L A-D R B 1$-exon3 Forward & 307 \\
\hline 24 & GCTCACCTCGCCGCTGCACTG & $H L A-D R B 1$-exon3 Reverse & \\
\hline 25 & GAGGTTGCACTCCAGCCTTT & F13 Forward & 200 \\
\hline 26 & ATGCCATGCAGATTAGAAA & F13 Reverse & \\
\hline
\end{tabular}




\section{Effect of different brands of collector tube types and storage temperature on gDNA yield and HLA PCR}

Three types of saliva collector tube were used in this study for examining the stability of the saliva samples. They were from Corning (USA), Tarsons (India), and Greiner Bio-One (Germany). Two randomly collected donor samples, A and B, were used for this parameter. The saliva samples in SSB were stored at RT and $4{ }^{\circ} \mathrm{C}$ for 1,2 , and 4 month periods and gDNA isolated by the method described above. The DNA yield and the quality parameters were checked. PCR of 2 exons, namely HLA-A-exon 2 and HLA-B-exon 2, were examined for these samples.

\section{F13 copy number determination}

The PCR for human coagulation factor XIII (F13) gene was carried out for 15 salivary gDNA using the primer pair (Table 1), as recommended by Khare et al. [15], using $10 \mathrm{ng}$ of salivary genomic DNA based on NanoDrop readings. The F13 PCR was set up by Q-PCR using 1X ThermoScientific Maxima SYBR green master mix, with $0.5 \mu$ of forward and reverse F13A1 primers, each at various required concentrations, and suitable amounts of template. The qPCR amplification was carried out for 40 cycles using a Qiagen Q-PCR machine (Qiagen, Germany) with the following thermal conditions: $95{ }^{\circ} \mathrm{C}$ for 5 min, $95{ }^{\circ} \mathrm{C}$ for $30 \mathrm{~s}, 51.1{ }^{\circ} \mathrm{C}$ for $30 \mathrm{~s}$, and $72{ }^{\circ} \mathrm{C}$ for $30 \mathrm{~s}$, followed by melt curve analysis.

\section{HLA PCR with 3 random samples of salivary gDNA using different polymerases}

Three donor samples (Sample ID \#s 6796, 6802, and 7117) from the set of 15 samples were used in this study. The concentrations of total gDNA for these samples per PCR reaction were $115 \mathrm{ng}, 30 \mathrm{ng}$, and 75 ng total gDNA, respectively. We intentionally chose samples with various DNA concentrations so that we could examine the minimum amount of gDNA required for amplification of all the HLA targets.

In the first set, PCR was carried out using Taq DNA polymerase alone; for the second set, both Taq DNA polymerase and AccuPrimeTaq polymerase were included in the PCR reaction, while in Set III, only AccuPrimeTaq was used.

\section{HLA PCR for additional 5 samples with equal gDNA concentrations}

Five samples (sample ID \#s 7113, 6761, 6763, 6765, and 6792) were selected and, based on their F13 copy numbers, were equalized to 1000 copies equivalent of F13 per reaction and used for HLA PCR. To compare the efficiencies of the amplifications, PCR carried out with Taq DNA polymerase alone and in combination with AccuPrimeTaq polymerases was used, as mentioned above.

\section{Preparation of Dried Saliva Spots (DSS)}

For experiments on generating DSS using Whatman 903 membrane, $1 \mathrm{ml}$ of the saliva samples in SSB, with sample IDs Test 1 , Test 2, and Test 3, were centrifuged at 13,000 rpm for $10 \mathrm{~min}$, and the pellet obtained was spotted on the sample spots provided on the Whatman 903 protein saver card. The spotted paper was used for extraction of DNA after overnight drying at room temperature.

\section{DNA extraction and HLA PCR from Dried Saliva spots (DSS)}

To extract DNA from DSS, the method of Strom et al. [16] was followed. Briefly, the method involved cutting one sample spot of the DSS with sterile scissors and transferring it to a $1.5-\mathrm{mL}$ microcentrifuge tube. $200 \mu \mathrm{l}$ of $5 \%$ Chelex-100 suspension (pre-heated to $100{ }^{\circ} \mathrm{C}$ for $10 \mathrm{~min}$ ) was then added, and the contents were incubated in a boiling water bath for $10 \mathrm{~min}$. The contents were centrifuged at 13,000 rpm for $10 \mathrm{~min}$ and supernatants used for PCR of all the HLA targets, as mentioned before. The DNA concentrations of the Test1, Test 2 and Test 3 DSS samples, measured by NanoDrop, were found to be $13.4,10.5$, and $43.7 \mathrm{ng} / \mu 1$, respectively.

Prior to HLA PCR, F13 copies for each of these samples was determined and found to be 800 copies, 168 copies, and 1039 F13 copies/ $\mu$ l, respectively. HLA PCR were carried out with equal amounts of gDNA equivalent to 1000 copies equivalent of F13, and the results analyzed. 
http://wjst.wu.ac.th

\section{Results}

\section{Properties of SSB}

The normal $\mathrm{pH}$ of human saliva is between 6.0 and 7.0 [17], hence the $\mathrm{pH}$ of the SSB was maintained at 5.5. EDTA is known to provide powerful antiseptic activities, and functions as an antimicrobial agent against bacteria and pathogenic yeast [18]. Kejnovsky and Kypr [19] have described the use of zinc ions for sedimentation of DNA from bacteriophages and, hence, we used this chemical in the preparation of SSB. Varied concentrations of zinc acetate, namely, 5mM, 50mM, $500 \mathrm{mM}, 1 \mathrm{M}$, and 1.5M, were tested as components in SSB. gDNA yield with SSB containing $500 \mathrm{mM}$ zinc acetate showed maximum gDNA yield (data not shown), hence, this concentration of zinc acetate was used for further studies. The prepared SSB was clear and showed no signs of any precipitation, even after storage at $4{ }^{\circ} \mathrm{C}$ for 9 months.

\section{Sampling of saliva}

Figure 1 depicts the step-wise protocol followed for sampling of saliva. The saliva samples after collection were stored in cold at 4 to $10^{\circ} \mathrm{C}$ until further use. The saliva collecting funnel was locally manufactured for 0.1 US \$ per piece.

\section{Extraction of DNA}

The amount of genomic DNA extracted from the saliva samples from all the 3710 HLA donor samples showed a high degree of inter-subject variation, ranging from $<1 \mu \mathrm{g}$ to as high as $1500 \mu \mathrm{g} / \mu \mathrm{l}$. The yields of gDNA from 125 randomly selected saliva samples from the HLA donors is shown in Table 2 as a representative example. Our results support the observations of Ehli et al. [20] and van Schie et al. [21], who reported variations in gDNA from saliva derived materials. The conventional method of assessing DNA quality is by measuring the $\mathrm{A}_{260} / \mathrm{A}_{280}$ ratio, which is between 1.7 and 2.0. The mean $\mathrm{A}_{260} / \mathrm{A}_{280}$ ratio for the 3710 saliva donor samples was found to be $\sim 1.9$.

\section{Effect of different brands of collector tube types and storage temperature on gDNA yield and HLA PCR}

The gDNA yield from the 3 types of collector tube was found to be $292,495,489 \mathrm{ng} / \mu 1$ for sample $\mathrm{A}$, while for sample $\mathrm{B}$, it was $606,427,392 \mathrm{ng} / \mu \mathrm{l}$. The $\mathrm{A}_{260} / \mathrm{A}_{280}$ ratios ranged between 2.05 to 2.12. The saliva samples that were stored in SSB at RT showed negligible PCR signals for 2 of the HLA genes tested, while the samples stored at $4{ }^{\circ} \mathrm{C}$ showed PCR signals of expected intensities (Figure 1).

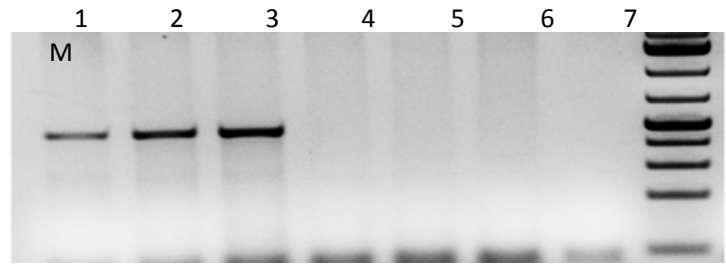

A

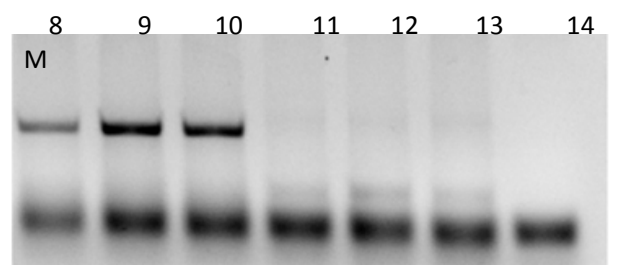

B

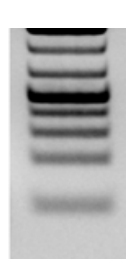

Figure 1 Effect of different brands of saliva collector tube and storage temperature on gDNA yield and HLA PCR

Panel A shows the PCR of HLA-A-Exon 2 gene in Corning tubes (lane 1), Tarson tubes (lane 2), and Greiner Bio-One (lane 3). Panel B shows the PCR of HLA-B-exon 2. Note the absence of PCR signals (lanes 4, 5, 6 and 11,2 and 13) in all the tubes stored at room temperature. Lanes 7 and 14 refer to no template control, and $\mathrm{M}$ refers to DNA molecular weight marker (75 bp to $20 \mathrm{~Kb}$ ). 
http://wjst.wu.ac.th

Figure 1A shows PCR of HLA-A-exon-2, while Figure 1B shows the PCR of HLA-B-exon 2. The gDNA was found to be stable at $4{ }^{\circ} \mathrm{C}$, irrespective of the types of saliva collection tube used.

\section{F13 copy determination}

Since the total yield of the salivary gDNA showed high variability, it was essential to determine the accurate concentration of DNA in each sample prior to PCR and Next Generation Sequencing (NGS). Fifteen arbitrarily selected salivary gDNA samples were processed for Q-PCR for F13 copy number determination, and the results indicated that the F13 copies between samples varied considerably, although equal amounts of salivary gDNA (10 ng) was taken for PCR. Also, there was no correlation between the observed F13 copies and genomic DNA concentration (Table 2).

Table 2 Determination of F13 copies in 15 randomly selected salivary gDNA samples

\begin{tabular}{cccc}
\hline & \multicolumn{3}{c}{ Salivary gDNA } \\
\hline S. N. & Sample & Concentration $(\mathbf{n g} / \boldsymbol{\mu l})$ & F13 (copies/ $\boldsymbol{\mu l})$ \\
\hline 1 & 7111 & 26.4 & 463 \\
2 & 7112 & 12.1 & 468 \\
3 & 7113 & 20.1 & 1835 \\
4 & 7114 & 13.8 & 181 \\
5 & 7116 & 13.8 & 698 \\
6 & 7117 & 14.2 & 813 \\
7 & 6761 & 18.3 & 8405 \\
8 & 6763 & 75.6 & 11,749 \\
9 & 6764 & 38.4 & 13,842 \\
10 & 6765 & 28.3 & 9885 \\
11 & 6766 & 34.2 & 39,457 \\
12 & 6768 & 80 & 27,796 \\
13 & 6792 & 16.9 & 3141 \\
14 & 6796 & 25.7 & 834 \\
15 & 6802 & 8.2 & 121 \\
\hline
\end{tabular}

The amplification plot and the melt curve analysis of the F13 Q-PCR is shown in Figure 2. Figure 2A shows the agarose gel electrophoresis of the F13 PCR product for all the 15 samples tested on agarose gel, which shows differences in the intensities of F13 PCR amplicons between samples, although their DNA yield was almost similar. Figure 2B shows the PCR signals from standard copies of F13 from $10^{5}$ to $10^{1}$ copies/ $\mu 1$.

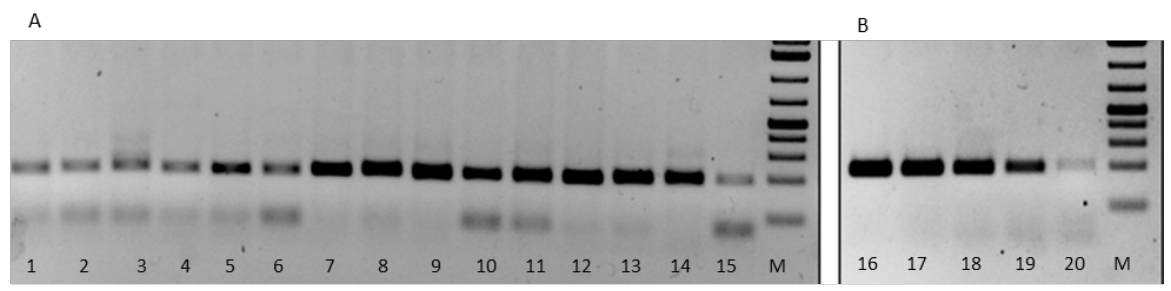

Figure 2 Agarose gel electrophoresis of F13 PCR amplicons from 15 salivary genomic DNA samples 
For panel A, lanes 1 to 15 refer to samples with sample ID \#s 7111, 7112, 7113, 7114, 7116, 7117, $6761,6763,6764,6765,6766,6768,6792,6796$, and 6802, respectively. Panel B shows the standard F13 copies of $10^{5}, 10^{4}, 10^{3}, 10^{2}$, and $10^{1}$ copies/ $\mu 1$. M: DNA molecular weight marker 75 bp to $20 \mathrm{~kb}$.

\section{HLA PCR with 3 random samples of salivary gDNA using different polymerases}

PCR amplification of all the twelve HLA targets for 3 random samples, namely, Sample ID \#s 6796, 6802, and 7117, with nearly 20,8, and $15 \mathrm{ng} / \mu \mathrm{lgDNA}$, respectively (Figure 3).

It is clear from Figure 3 that the intensities of the PCR signals of several of the genes of our HLA PCR panel (except reaction 7) were very similar, although the DNA concentration per reaction used was different. This result certainly indicated that the quantitation methodology followed by NanoDrop readings is not an accurate method for the estimation of yields of genomic DNA from salivary DNA samples, and one would need an alternate method to use equal amounts of gDNA for downstream processes per reaction to minimize variations in amplicon concentrations post-PCR. Also, we found that the PCR signals were much more pronounced when 2 polymerases were used in the PCR reaction (Figure 3, panel A vs D, panel B vs E, and panel C vs F) in place of the use of a single type of polymerase.
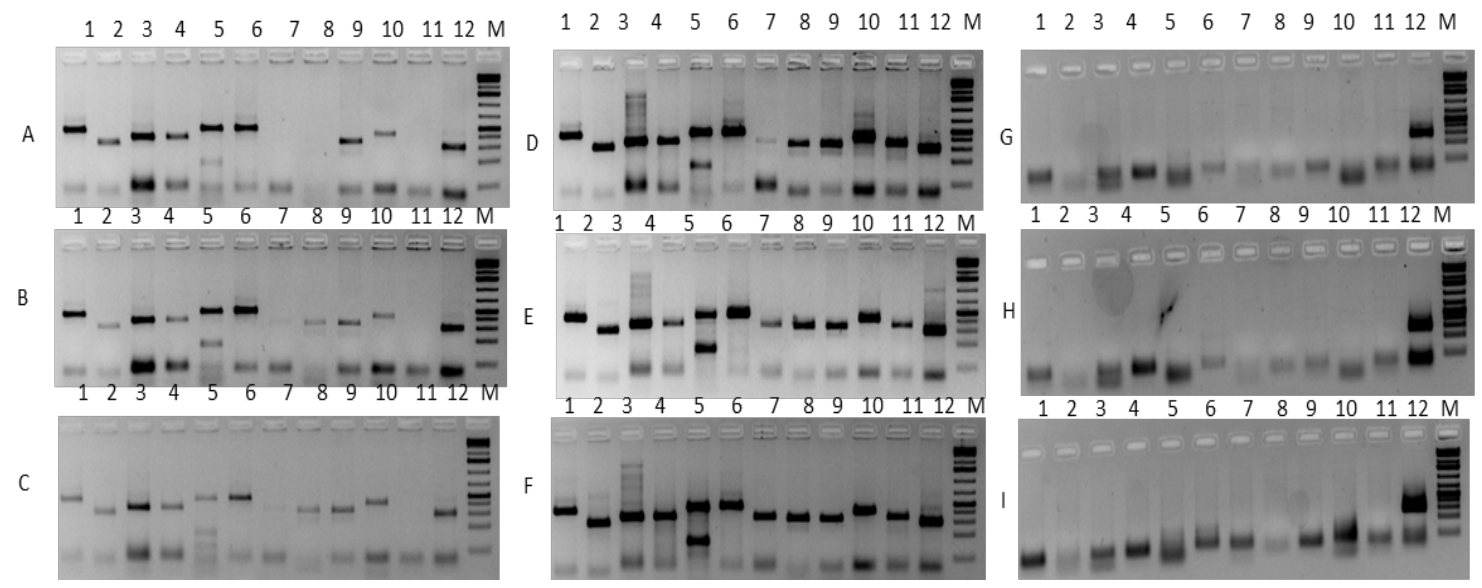

Figure 3 HLA PCR of 3 randomly selected salivary gDNA using Taq polymerase without and with AccuPrimeTaq polymerase and AccuPrimeTaq alone

Panels A, B, and C show the PCR with Taq DNA polymerase for 3 samples, namely, sample ID \#s 6796, 6802, and 7117, respectively, while panels D, E, and F show HLA PCR for all the twelve target genes using Taq polymerase and AccuPrimeTaq polymerase. Panels G, H, and I depict the HLA PCR of the same samples with AccuPrimeTaq alone. Note that the reactions 7, 8, 11 show poor PCR signals with Taq alone, while the signals are pronounced for the same reactions when 2 polymerases are used together. It is clear that, except for target \#12, none of the samples showed any visible amplification with AccuPrimeTaq alone. $\mathrm{M}$ denotes DNA molecular weight marker 75 bp to $20 \mathrm{~Kb}$.

F13 copies in selected salivary gDNA in 5 samples

From the fifteen extracted salivary gDNA, we randomly selected a set of another 5 saliva donor sample DNAs, namely, from Sample ID \#s 7113, 6792, 6761, 6765, and 6763, for further studies. Although the concentration of the gDNA in these samples by NanoDrop readings were similar (Table 3), their F13 copies varied significantly. We carried out PCR of the complete HLA panel and observed that 
the HLA PCR in all the samples were not uniform (Figure 4). As observed before, there was dramatic improvement in PCR signals for all the tested samples when both Taq and AccuPrimeTaq was used in the reaction mix (Figure 4, panels $\mathrm{A}+$ to $\mathrm{J}+$ ), and the intensities of the signals were much more than observed with Taq polymerase alone (Figure 4, panels A to J).

Table 3 F13 copies in randomly selected 5 salivary gDNA extracted from 5 samples

\begin{tabular}{ccccc}
\hline S.N. & Sample & Ct & Input F13 copies & F13copies/ $\boldsymbol{\mu l}$ \\
\hline 1 & NTC & - & - & - \\
3 & $10^{5}$ & 20.2 & $1,00,000$ & 97,359 \\
4 & $10^{4}$ & 24.1 & 10,000 & 12,531 \\
5 & $10^{3}$ & 29.69 & 1,000 & 657 \\
6 & $10^{2}$ & 32.76 & 100 & 131 \\
7 & $10^{1}$ & 37.74 & 10 & 10 \\
8 & Test 1 & 29.19 & - & 855 \\
9 & Test 2 & 27.53 & - & 2,060 \\
10 & Test 3 & 25.3 & - & 6,660 \\
11 & Test 4 & 24.22 & - & 11,763 \\
12 & Test 5 & 28.2 & - & 1,443 \\
\hline
\end{tabular}
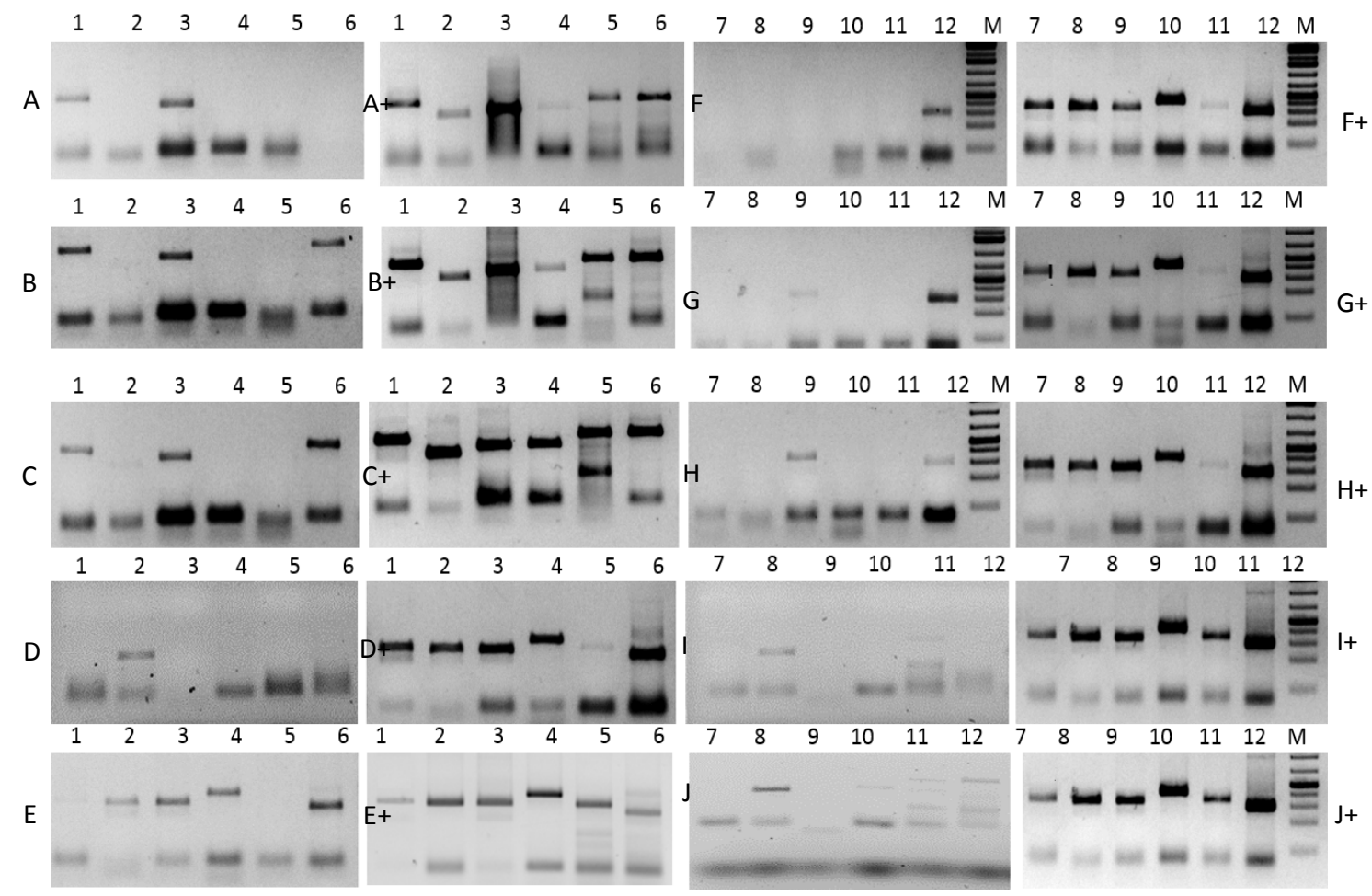

Figure 4 HLA PCR of Class I and Class II genes using salivary genomic DNA as template 
http://wjst.wu.ac.th

Panels A to J refers to HLA PCR products obtained using Taq DNA polymerase alone with DNA of samples with ID \#s 7113, 6792, 6761, 6765, and 6763, respectively. Panels A+ to J+ refers to HLA PCR achieved using Taq and AccuPrimeTaq polymerase. Lanes 1 to 6 represent the PCR of HLA Class I genes, while lanes 7 to 12 are of PCR of HLA Class II genes.

From both Figures 3 and 4, it is clear that with the use of 2 DNA polymerases, namely Taq DNA polymerase and AccuPrimeTaq polymerase, one could achieve PCR of all the target genes with merely 10 ng of F13 equivalent salivary genomic DNA. Our results demonstrate a synergy between Taq DNA polymerase and AccuPrimeTaq DNA polymerase, which has hitherto been unreported.

DNA yield and F13 copies for 3 DSS samples

We opted to use fresh saliva in SSB for this study. Fresh saliva was collected from 3 donors, and these samples, designated as Test 1 , Test 2 , and Test 3 , were kept in cold ( 4 to $10{ }^{\circ} \mathrm{C}$ ) for 1 week. The saliva samples were spun and the pellet was used for extraction of genomic DNA as described before. The genomic DNA from the 3 test samples, Test 1, Test 2, and Test 3, from DSS was found to be 13.4, 10.5 , and $43.7 \mathrm{ng} / \mu \mathrm{l}$, as judged by NanoDrop Spectrophotometer readings, while the F13 copies by F13 Q-PCR were 800,166 , and 1039 copies/ $\mu 1$, respectively.

Initially, when we processed these salivary gDNA samples for determination of number of copies of F13 content for these samples, we failed to see any signal for the F13 Q-PCR (Table 4).

Table 4 gDNA concentration and F13 copies determination from 3 human DSS samples

\begin{tabular}{ccccc}
\hline S.N. & Sample ID & $\begin{array}{c}\text { DNA concentration } \\
\text { ng/ } \boldsymbol{\mu l} \\
\text { (Nanodrop readings) }\end{array}$ & $\begin{array}{c}\text { F13 copies/ } \boldsymbol{\mu l} \\
\text { (before washing the } \\
\text { saliva pellet) }\end{array}$ & $\begin{array}{c}\text { F13 copies/ } \boldsymbol{\mu l}(\mathbf{a f t e r} \\
\text { washing step*) }\end{array}$ \\
\hline 1 & Test 1 & 13.4 & Nil & 800 \\
2 & Test 2 & 10.5 & Nil & 166 \\
3 & Test 3 & 43.7 & Nil & 1039 \\
\hline
\end{tabular}

* Refers to saliva pellet obtained after centrifugation of $1 \mathrm{ml}$ saliva in SSB, washed once with $1 \mathrm{ml}$ of 25 mMTris. $\mathrm{Cl}, \mathrm{pH} 8.0$, prior to gDNA extraction procedure, as mentioned in $\mathrm{M} \& \mathrm{M}$ section.

The above data clearly indicates that one of the components of the DSS derived gDNA was inhibiting the F13 Q-PCR. We realized that, since inhibition of SYBR by EDTA is known [22], it appeared possible that traces of EDTA from SSB might be present in the gDNA derived from DSS. Hence, when we took another aliquot of the saliva pellet of these 3 samples, we washed the pellet with 1

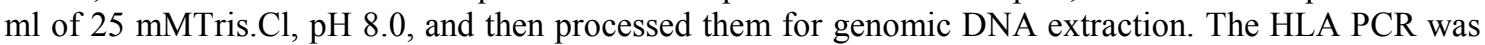
carried out using 1000 F13 copies equivalent (10 ng salivary gDNA), and the results indicate successful HLA PCR amplifications of all the targets (Figure 5). Figure 5A shows the HLA PCR of all the twelve targets from DSS of test sample 1, while Figures 5B and 5C depict the HLA PCR from DSS of test sample 2 and 3 , respectively. 

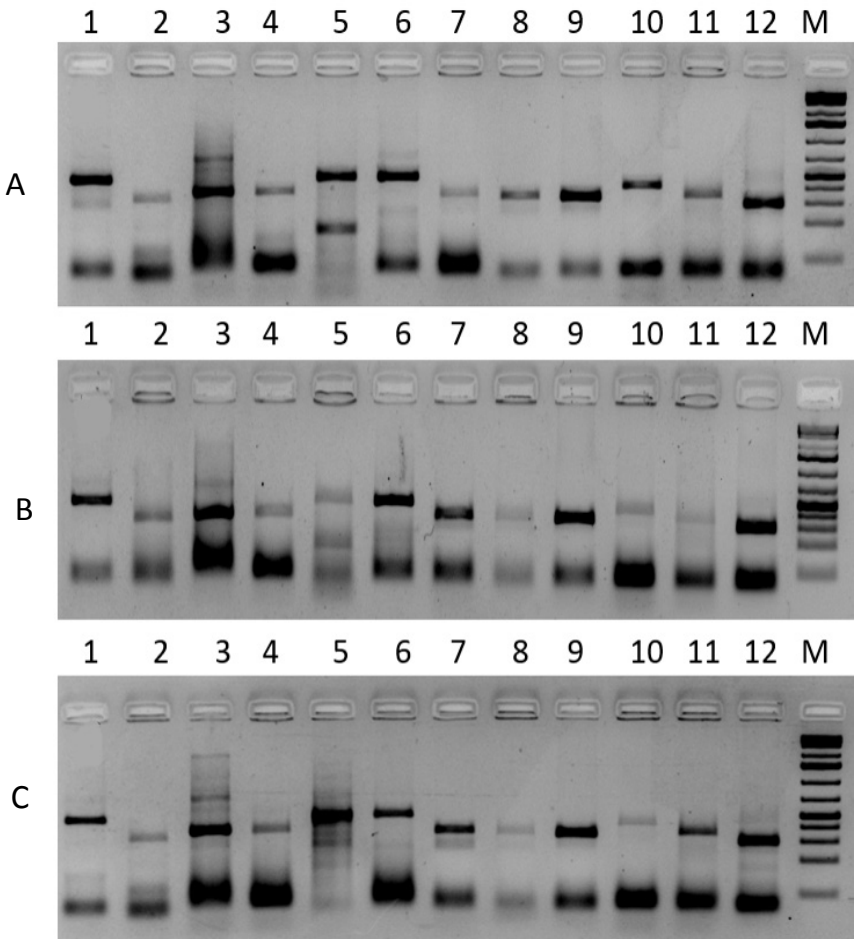

Figure 5 HLA PCR from 3 dried saliva spots (DSS)

Panels A, B, and C refer to Test 1, Test 2, and Test 3 samples. Note the strong signal of all the HLA PCR targets using 1000 F13 copies equivalent of genomic DNA.

\section{Discussion}

The protocol of extracting DNA from saliva as described in the present article is a rapid and easy method, since it does not involve the use of any expensive kits/columns, reagents, or hazardous chemicals. Also, the entire process of gDNA extraction is cost-effective and easily scalable. The quantity and quality of extracted DNA achieved was shown to be adequate for PCR-based SSP, SSO, and SBT typing. The total gDNA yield from $1 \mathrm{ml}$ saliva appears to be sufficient for the PCR of all the HLA targets and is an attractive and interesting alternative to all the methods reported in the literature, supporting the observations of Chacon-Cortes et al. [23], who claimed that modified salting out method is the optimal method for genomic DNA extraction from blood.

Our report on the concept of generating DSS for extraction of gDNA is novel and would have immense applications in forensic sciences and DNA diagnostics. DSS has the advantages of easy transport, minimal contamination due to the dry state of the material, and no cold-chain requirement for storage or transport. Our results on successful extraction of gDNA from 3 arbitrarily selected DSS samples and positive HLA PCR signal from their extracted DNAs opens up the possibility of its usage as a sensitive and reliable method for HLA typing. Reports by Hansen et al. [24] suggest that, although 84\% of the saliva could be used for genotyping and PCR amplification, none of the DNA from Whatman FTA cards could be PCR amplified, and that the DNA yield from buccal cells on FTA cards was very low. In the light of the above report, our observations of successful amplification of genomic DNA from saliva on Whatman 903 filter papers is interesting, and worth pursuing in epidemiological studies.

Our results on higher and successful PCR intensities, with 2 DNA polymerases in comparison to PCR achieved with a single polymerase, support the observations of such a synergy of polymerases 
reported by Hedman et al. [25], where 2 polymerases, ExTaq Hot Start and PicoMaxx High Fidelity, were combined and shown to have improved DNA profile quality through better resistance to PCR inhibitors. While regular Taq polymerase has activity at room temperature, leading to the possibility of the generation of non-specific products, AccuprimeTaq is a hot start polymerase that has a thermostable AccuPrime protein that enhances primer-template hydridization in every PCR cycle [25], leading to the generation of only specific products, with minimal non-specific products. It is tempting to speculate that blending of these 2 polymerases might work synergistically to achieve the desired PCR result. Also, the PCR additives we used have additives that work best with high GC content templates and, hence, blending inhibitor resistant polymerase buffer systems further must play a role in enhancing the success rates of PCR tested here.

AccuPrime-High Fidelity Taq polymerase is a blend of Taq polymerase, a processivity-enhancing protein, and a higher fidelity proofreading polymerase from Pyrococcus species GB-D, with negligible activity at room temperature. From our present study, it is clear that the inclusion of 2 polymerases offers a synergistic effect, yielding a strong PCR signal for the tested targets and, since AccuPrimeTaq has no significant effect on base substitution errors due to enhanced processivity, one could use this enzyme for HLA PCR along with the regularly used Taq DNA polymerase. The reasons for no visible amplifications of all the HLA targets except DRB1, Exon 2 gene using AccuPrimeTaq, alone are is rather surprising and difficult to explain at this stage.

Garbieri et al. [26] have observed that better quality DNA was achieved from fresh saliva, and that the quality and quantity of DNA was best when saliva was stored in a suspension buffer, a proprietary solution from Oragen commercial kit. Since we realized, for a large scale, that using the commercially available kits would not have a cost-advantage, our disclosure on making saliva stabilization buffer inhouse would be useful.

Recent reports suggest that there is no significant difference in precision and accuracy between the HLA typing results of blood and saliva samples [24,27], and that the leucocytes of saliva represent the main source of DNA [28]. Hence, the present work on disclosure of extracting salivary gDNA assumes critical importance. We have observed identical results in the HLA allele typing for gDNA isolated from the blood or the saliva from the same donor (data not shown), supporting the observations of Juhos et al. [27].

FXIIIa (F13) is a highly polymorphic gene loci on the short arm of chromosome 6 as the HLA genes [10], and identification of the copy number of F13 in the genomic samples could be safely used for achieving similar PCR amplification of different HLA target genes. Moreover, there are advantages to using F13 as IC in our case, since it does not require any reagents, gene products, or plasmids to be added extraneously, as F13 can be easily amplified directly from the same source of gDNA samples that are intended for HLA typing by PCR. The method of F13 Q-PCR described here does not lead to primerdimer formation, hence, during PCR, one could expect formation of specific PCR products, since primer dimers compete with the target product and cause reduced amplification efficiency and a less successful PCR. Also, our observation of successful PCR of all the target HLA genes using merely 1000 copies of the F13 equivalent gDNA preparations (10 ng of gDNA) supports the reports of Ozaki et al. [29].

Also, a recent paper by Schoff et al. [30] demonstrates that DNA concentrations achieved by extraction from buccal samples have varied over a wide range, from 4.8 to $86.1 \mathrm{ng} / \mu \mathrm{l}$ of DNA, and that DNA concentrations lower than $2 \mathrm{ng} / \mu \mathrm{l}$ have been found empirically to compromise genotyping results severely. Hence, we used a minimum of 5 to $10 \mathrm{ng}$ of gDNA for all the HLA PCR and, hence, when a few donor samples failed to show signals for HLA PCR, we wanted to enhance the PCR signals using higher efficient polymerases, rather than increasing the amount of gDNA, since higher template is known to result in spurious amplifications and, eventually, inaccurate and ambiguous HLA typing. Moreover, it is also well known that HLA typing is accurate and without bias if the concentration of DNA used is $\sim 10$ ng [31].

HLA genes are usually typed with targeted sequencing methods: either long-read sequencing or long-insert short-read sequencing. The use of second-generation sequencing methods, through sequencing a single DNA strand in isolation, aids in single allele definition at primary HLA typing as against different molecular techniques and serological testing methods employed earlier. The only limitation of 
http://wjst.wu.ac.th

this technique is the generation of longer read lengths, which requires the need to perform multiple overlapping sequences to achieve full genes [12]; just recently, this limitation has been overcome by the development of Pacific Biosciences' Single Molecule Real Time (SMRT) DNA sequencing technology to generate exceptionally long reads of $\sim 3 \mathrm{~kb}$ or more of a HLA class I gene sequence and, thus, determine the phase of the resolving polymorphisms seen with earlier methods. A recent paper by Xie et al. [32] describes the use of xHLA, an algorithm for HLA typing based on translated short reads, exhaustive multiple sequence alignment-based alignment expansion, and, finally, HLA typing.

Irrespective of any method, to employ the critical part of all the assays/methodologies available, what remains critical is the availability of a correct quality and quantity of DNA that is used for generating PCR amplicons, hence, our work on accurate determination of gDNA and successful PCRs using 2 polymerases with synergistic functions assumes critical importance.

The most commonly used NGS platforms available are Miseq, Hiseq, and Nexseq, from Ilumina, Ion Torrent Personal Genome Machine and Proton, from Life Technologies, 454 GS Sequencers from Roche, Pacific Bioscience RS etc. Although each of the above NGS sequencers are unique in their properties and function, they use similar protocols that are comprised of library preparation and quantification, template synthesis, sequencing, and data analysis. Hence, our present paper disclosing a cost-effective methodology for an accurate HLA typing by Sanger sequencing appears clinically relevant, and cost-effective, too.

Although NGS is cheaper than Sanger sequencing, it still remains an expensive technique for some laboratories having limited infrastructure. Also, the data analysis is time consuming, and needs big storage space and bioinformatics expertise, mainly due to the high amounts of data resulting from the sequencing experiments [33].

Polymorphisms in the MHC locus have been shown to influence many critical biological traits and the susceptibility of the individuals to autoimmune, infectious, and neurological diseases [34]. Literature reports highlight the associations of specific HLA allele types as a pharmacogenetic marker [35]. Some of them include the HLA-DRB1 gene that shows the strongest association to rheumatoid arthritis, HBV infection driven by variants and alleles around HLA-DPB1 [34], and $H L A-B * 57: 01$ allele as a marker to predict hypersensitive reactions (HSR) to Abacavir, a nucleoside reverse-transcriptase inhibitor with activity against the human immunodeficiency virus (HIV), to name a few [35,36]. Castella et al. [37] suggested a simple and robust PCR based assay for the screening of this pharmacogenomic marker directly from buccal swabs without DNA extraction, which is cost-effective. Another study showed that psoriasis patients carry the same genetic variants as HIV controllers/non-progressors, and that they are particularly enriched for the protective allele HLA-B*57:01 [38,39].

HLA has, therefore, also become an important tool for understanding the pathogenesis of various infectious diseases; the alleles or HLA haplotypes inherited by an individual can predict several risk and protective factors related to infections caused by various agents. Hence, our work on effective use of human saliva for HLA PCR and typing assumes critical importance and is clinically significant. Salivaas DSS with use of 2 DNA polymerases would certainly promote diagnostic and forensic laboratories to achieve a higher quality of DNA and aid in the analysis and interpretation of pharmacogenetic data.

\section{Conclusions}

We have successfully demonstrated the PCR amplification of all the polymorphic HLA target genes using human saliva and saliva dried spots as the starting material. The amount of DNA required for such amplification could be quantitated accurately using the F13 gene as an internal control, and PCR amplification achieved using DNA of $\sim 10 \mathrm{ng} / \mu \mathrm{l}$ would find its utility in the scenario of limited sample availability, as in forensic science. 
http://wjst.wu.ac.th

\section{Acknowledgements}

We thank Mr. Chandrashekar, MD, Intermedics, Bangalore, India, for designing and manufacturing the saliva collecting funnels for our study. The authors are thankful to Dr. K.N. Sridhar and Dr. Gautham Nadig for their constant support and encouragement. Cancyte Technologies Pvt. Ltd. is totally funded by Sri Sharada Sringeri Peetam, Bangalore, India.

\section{References}

[1] SY Choo. The HLA system: Genetics, immunology, clinical testing, and clinical implications. Yonsei Med. J. 2007; 48, 11-23.

[2] M Wittig, JA Anmarkrud, JC Kässens, S Koch, M Forster, E Ellinghaus, JR Hov, S Sauer, M Schimmler, M Ziemann, S Görg, F Jacob, TH Karlsen and A Franke. Development of a highresolution NGS-based HLA-typing and analysis pipeline. Nucleic Acids Res. 2015; 43, e70.

[3] S Ghatak, RB Muthukumaran and SK Nachimuthu. A simple method of genomic DNA extraction from human samples for PCR-RFLP analysis. J. Biomol. Tech. 2013; 24, 224-31.

[4] M Tiwari. Science behind human saliva. J. Nat. Sci. Biol. Med. 2011; 2, 53-8.

[5] R Cascella, L Stocchi, C Strafella, I Mezzaroma, M Mannazzu, V Vullo, F Montella, G Parruti, P Borgiani, F Sangiuolo, G Novelli, A Pirazzoli, S Zampatti and E Giardina. Comparative analysis between saliva and buccal swabs as source of DNA: Lesson from HLA-B*57:01 testing. Pharmacogenomics 2015; 16, 1039-46.

[6] JW Galloway, BJ Keijser and DM Williams. Saliva in studies of epidemiology of human disease: The UK Biobank project. Periodontology 2000 2016; 70, 184-95.

[7] T Kojima, R Uchihi, T Yamamoto, K Tamaki and Y Katsumata. DNA typing of the three HLAClass II loci from saliva stains. Nihon Hoigaku Zasshi 1993; 47, 380-6.

[8] P Terasaki, D Chia and L Sugich. Saliva as DNA source for HLA typing. Hum. Immunol. 1998; 59, 597-8.

[9] M Allen, T Saldeen and U Gyllensten. PCR-based DNA typing of saliva on stamps and envelopes. Biotechniques 1994; 17, 546-52.

[10] M Souri, T Osaki and A Ichinose. The non-catalytic B subunit of coagulation factor XIII accelerates fibrin cross-linking. J. Biol. Chem. 2015; 290, 12027-39.

[11] S Suguna, DH Nandal, S Kamble, A Bharatha and R Kunkulol. Genomic DNA isolation from human whole blood samples by non-enzymatic salting out method. Int. J. Pharm. Pharm. Sci. 2014; 6, 198-9.

[12] NP Mayor, J Robinson AJM McWhinnie, S Ranade, K Eng, W Midwinter, WP Bultitude, ChenShan Chin, B Bowman, P Marks, H Braund, JA Madrigal, K Latham and SGE Marsh. HLA typing for the next generation. PLoS One 2015; 10, e0127153.

[13] V Lange, I Böhme, J Hofmann, K Lang, J Sauter, B Schöne, P Paul, V Albrecht, JM Andreas, DM Baier, J Nething, U Ehninger, C Schwarzelt, J Pingel, G Ehninger and AH Schmidt. Cost-efficient high-throughput HLA typing by MiSeq amplicon sequencing. BMC Genomics 2014; 15, 63.

[14] Y Itoh, N Mizuki, T Shimada, F Azuma, M Itakura, K Kashiwase, E Kikkawa, JK Kulski, M Satake and $\mathrm{H}$ Inoko. High-throughput DNA typing of HLA-A, -B, -C, and -DRB1 loci by a PCR-SSOPLuminex method in the Japanese population. Immunogenetics 2005; 57, 717-29.

[15] P Khare, V Raj, S Chandra and S Agarwal. Quantitative and qualitative assessment of DNA extracted from saliva for its use in forensic identification, J. Forensic Dent. Sci. 2014; 6, 81-5.

[16] GE Strøm, MG Tellevik, K Hanevik, N Langeland and B Blomberg. Comparison of four methods for extracting DNA from dried blood on filter paper for PCR targeting the mitochondrial Plasmodium genome. Trans. R. Soc. Trop. Med. Hyg. 2014; 108, 488-94.

[17] SP Humphrey and RT Williamson. A review of saliva: normal composition, flow, and function. $J$. Prosthet. Dent. 2001; 85, 162-69.

[18] MRW Brown and RME Richards. Effect of ethylenediamine tetra acetate on the resistance of Pseudomonas aeruginosa to antibacterial agents. Nature 1965; 207, 1391-3. 
http://wjst.wu.ac.th

[19] E Kejnovsky and J Kypr. DNA extraction by zinc. Nucleic Acids Res. 1997; 25, 1870-1.

[20] EA Ehli, T Lengyel-Nelson, JJ Hudziak and GE Davies. Using a commercially available DNA extraction kit to obtain high quality human genomic DNA suitable for PCR and genotyping from 11-year-old saliva saturated cotton spit wads. BMC Res. Notes 2008; 1, 133.

[21] RC van Schie and ME Wilson. Saliva: A convenient source of DNA for analysis of bi-allelic polymorphisms of $\mathrm{Fc}$ gamma receptor IIA (CD32) and Fc gamma receptor IIIB (CD16). $J$. Immunol. Meth. 1997; 208, 91-101.

[22] WA Al-Soud and P Rådström. Purification and characterization of PCR-inhibitory components in blood cells. J. Clin. Microbiol. 2001; 39, 485-93.

[23] D Chacon-Cortes, LM Haupt RA Lea and LR Griffiths. Comparison of genomic DNA extraction techniques from whole blood samples: a time, cost and quality evaluation study. Mol. Biol. Rep. 2012; 39, 5961-66.

[24] TV Hansen, MK Simonsen, FC Nielsen and YA Hundrup. Collection of blood, saliva, and buccal cell samples in a pilot study on the Danish nurse cohort: Comparison of the response rate and quality of genomic DNA. Cancer Epidemiol. Biomarkers Prev. 2007; 16, 2072-6.

[25] J Hedman, ANordgaard, C Dufva, B Rasmusson, R Ansell and P Rådström. Synergy between DNA polymerases increases polymerase chain reaction inhibitor tolerance in forensic DNA analysis. Anal. Biochem. 2010; 405, 192-200.

[26] TF Garbieri, DT Brozoski, TJ Dionísio, CF Santos and LT Neves. Human DNA extraction from whole saliva that was fresh or stored for 3,6 or 12 months using five different protocols. J. Appl. Oral Sci. 2017; 25, 147-58.

[27] S Juhos, G Horváth, A Bérces, C Lind, D Monos, M Tayeb and R Iwasiow. Next-generation sequencing-based HLA typing of saliva and blood samples from the same donors produces concordant typing results. Hum. Immunol. 2014; 75, 115.

[28] CM Cianga, I Antohe, M Zlei, D Constantinescu and P Cianga. Saliva leukocytes rather than saliva epithelial cells represent the main source of DNA. Revista Română de Medicină de Laborator. 2016; 24, 31-44.

[29] Y Ozaki, S Suzuki, K Kashiwase, A Shigenari, Y Okudaira, S Ito, A Masuya, F Azuma, T Yabe, S Morishima, S Mitsunaga, M Satake, M Ota, Y Morishima, JK Kulski, K Saito, H Inoko and T Shiina. Cost-efficient multiplex PCR for routine genotyping of up to nine classical HLA loci in a single analytical run of multiple samples by next generation sequencing. BMC Genomics 2015; 16, 318.

[30] G Schöfl, K Lang, P Quenzel, I Böhme, J Sauter, JA Hofmann, J Pingel, AH Schmidt and V Lange. 2.7 million samples genotyped for HLA by next generation sequencing: lessons learned. $B M C$ Genomics 2017;18:161.

[31] X Xiao-Qing, C Ya-Nan, X Zheng, S Qin-Xin and Z Guo-Hua. Establishment of Cloning and Sequencing Method for High-Resolution HLA-B Genotype Assay. Chin. J. Anal. Chem. 2014; 42, 1574-9.

[32] C Xie, ZX Yeo, M Wong, J Piper, T Long, EF Kirkness, WH Biggs, K Bloom, S Spellman, C Vierra-Green, C Brady, RH Scheuermann, A Telenti, S Howard, S Brewerton, Y Turpaz and JC Venter. Fast and accurate HLA typing from short-read next-generation sequence data with xHLA. Proc. Natl. Acad. Sci. USA 2017; 114, 8059-64.

[33] C Lucan, Laura-Ancuta Pop, A Florian, V Pileczki, B Petrushev, D Dima, I Frinc, I BerindanNeagoe, A Irimie, C Berce, IS Florian, A Bojani and C Tomuleasa. HLA genotyping using next generation sequencing. Rom. J. Intern. Med. 2016; 54, 98-104.

[34] V Matzaraki, V Kumar, C Wijmenga and A Zhernakova. The MHC locus and genetic susceptibility to autoimmune and infectious diseases. Genome Biol. 2017; 18, 76.

[35] L Stocchi, R Cascella, S Zampatti, A Pirazzoli, G Novelli and E Giardina. The pharmacogenomic HLA biomarker associated to adverse abacavir reactions: Comparative analysis of different genotyping methods. Curr. Genomics 2012; 13, 314-20.

[36] S Mallal, E Phillips, G Carosi, JM Molina, C Workman, J Tomazic, E Jägel-Guedes, S Rugina, O Kozyrev, JF Cid, P Hay, D Nolan, S Hughes, A Hughes, S Ryan, N Fitch, D Thorborn and A 
http://wjst.wu.ac.th

Benbow. HLA-B*5701 screening for hypersensitivity to abacavir. N. Engl. J. Med. 2008; 358, 56879.

[37] R Cascella, C Strafella, M Ragazzo, S Zampatti, P Borgiani, S Gambardella, A Pirazzoli, G Novelli and E Giardina. Direct PCR: A new pharmacogenetic approach for the inexpensive testing of HLAB*57:01. Pharmacogenomics J. 2015; 15, 196-200.

[38] S Raychaudhuri, C Sandor, EA Stahl, J Freudenberg, H Lee, X Jia, L Alfredsson, L Padyukov, L Klareskog, J Worthington, KA Siminovitch, SC Bae, RM Plenge, PK Gregersen and PI de Bakker. Five amino acids in three HLA proteins explain most of the association between MHC and seropositive rheumatoid arthritis. Nat. Genet. 2012; 44, 291-6.

[39] H Chen, G Hayashi, OY Lai, A Dilthey, PJ Kuebler, TV Wong, MP Martin, MAF Vina, GM Vean, M Wabl, KS Leslie, T Maurer, JN Martin, SG Deeks, M Carrington, AM Bowcock, DF Nixon and W Liao. Psoriasis patients are enriched for genetic variants that protect against HIV-1 disease. PLoS Genet. 2012; 8, 1-12. 